\title{
TABLES, MAPS, AND FIGURE
}

\section{TABLES}

1. Salt-Related Loans from World Powers, $1895^{-1939} / 5^{2-53}$

2. Salt Prices in Hebei Counties / 62

3. Zhang Lineage Landholdings in Fanzhuang, 1930 / $\quad 169$

4. Yao Lineage Landholdings in Fanzhuang, 1930 / 170

5. Qian Foji Village Land Revolution Survey $/ \quad 3{ }^{6-17}$

\section{MAPS}

1. North China, showing the Changlu salt works / 4

2. The lower North China plain and the old course of the Yellow River / 5

3. Earth salt production areas targeted for suppression by the Nationalist government / $7 I$

4. Nanle County, Hebei Province, $1935 /{ }_{17} 8$

5. Thousand Buddhas Market in West Nanle / 243

FIGURE

1. Kuomintang suppression of the market and the occurrence of saltmakers' mobilizations / 298 
